LiminaR. Estudios Sociales y Humanísticos

ISSN: 1665-8027

liminar.cesmeca@unicach.mx

Centro de Estudios Superiores de México y

Centro América

México

García Meza, Norma Esther

El discurso funerario de Lucas Macías en Al filo del agua

LiminaR. Estudios Sociales y Humanísticos, vol. VII, núm. 2, diciembre, 2009, pp. 56-68

Centro de Estudios Superiores de México y Centro América

San Cristóbal de las Casas, México

Disponible en: http://www.redalyc.org/articulo.oa?id=74516319005

Cómo citar el artículo

- Número completo

- Más información del artículo

Página de la revista en redalyc.org

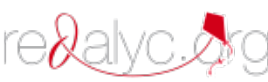

Sistema de Información Científica

Red de Revistas Científicas de América Latina, el Caribe, España y Portugal

Proyecto académico sin fines de lucro, desarrollado bajo la iniciativa de acceso abierto 


\title{
El discurso funerario de LuCas Macías en Al filo del aGUA ${ }^{1}$
}

\author{
Norma Esther García Meza
}

Resumen: En la provincia mexicana, los velorios y los enterramientos entretejen rituales y diversas prácticas como el repaso detallado de las causas de la muerte y valoraciones sobre la vida del difunto, convirtiéndose en eventos de socialización donde el lenguaje tiene un lugar destacado. Animados por las bebidas propias de la región donde ocurren, los asistentes hablan del difunto, de sus deudos y discuten asuntos éticos y filosóficos, cotidianos y trascendentales, asociados a la vida y a la muerte. Dando lugar, así, a la construcción de discursos funerarios eminentemente orales. Uno de estos discursos es recreado artísticamente en la novela de Yánezen la figura de Lucas Macías.

Palabras clave: discurso funerario, lenguaje oral, rituales mortuorios.

Enviado a dictamen: 10 de agosto de 2009

Aprobación: 01 de octubre de 2009

Revisiones: 1

Norma Esther García Meza, doctora en Letras, por la Universidad Nacional Autónoma de México (UNAM), Investigadora de tiempo completo en el Centro de Estudios de la Cultura y la Comunicación de la Universidad Veracruzana (UV). Temas de especialización: imagen artística de la memoria en la literatura mexicana, estudios de la cultura y de género. Correo electrónico: ngarcia35@hotmail.com.
Abstract: In the Mexican countryside, funerary rites interweave numerous ritual practices, such as detailed analyses of the causes of death and evaluations of the life of the deceased, thus becoming social events in which language plays a prominent role. Often animated by locally-produced alcoholic beverages, participants in these rituals talk about the deceased and his or her relatives, and also discuss ethical and philosophical issues associated with life and death. This results in the construction of funeral speeches strongly rooted in oral tradition. One such speech is artistically recreated in Yáñez's novel in the character of Lucas Macías.

Key words: funeral speeches, oral language, funerary rituals.

\section{Introducción}

L a identificación del proceso de construcción de la memoria colectiva, como imagen artística central _en Al filo del agua, fue una de las aportaciones de la investigación que realicé sobre la novela de Agustín Yáñez. ${ }^{2}$ Sostuve, entonces, que tal proceso era posible gracias a la voz de lo popular y lo colectivo enunciada por Lucas Macías ${ }^{3}$ y analicé el cúmulo de atributos que lo caracterizan, pero apenas me detuve en el que lo distingue como poseedor de un discurso funerario basado en la construcción oral de epitafios. Es por ello que, en el presente artículo, me ocuparé con mayor detenimiento 
de dicho rasgo por medio del cual otorga a los muertos el derecho de pertenecer y permanecer en la memoria colectiva, ${ }^{4}$ distinguiéndose así de los otros discursos funerarios presentes en la novela. ${ }^{5}$

Para el análisis que me propongo realizar es preciso considerar primero que, mediante una serie de atributos y características expresadas tanto por los personajes como por el narrador, ${ }^{6}$ Lucas Macías se perfila en la novela como un ser profundamente franco y vivaz, capaz de festejar la vida, de burlarse de imposiciones, de ridiculizar lo autoritario, de reírse de los fingimientos y de enunciar un discurso funerario carente completamente de dramatismo, desazón o pesar.

Ahora bien, de todas las enunciaciones que se refieren a él, me interesa destacar las expresadas por el narrador, mediante las cuales logra tres propósitos: a) distinguirlo de los demás viejos del pueblo ("No es el más viejo —abundan longevos en el pueblo-; pero entre los viejos es el de mejor memoria y más vivo ingenio"); ${ }^{7}$ b) situarlo en el ámbito de los velorios (“«Filósofo de velorio» suelen llamarlo burlándosele, pues que no falta a ninguno y allí rompe la vena de sus consideraciones y máximas") ${ }^{8}$ y c) ubicarlo recorriendo el cementerio ("Inagotables cómputos de Lucas Macías, que como todos los años va de tumba en tumba, este dos de noviembre de mil novecientos nueve, día de muy espléndida tarde"). ${ }^{9}$ La primera declaración hace énfasis en dos de los atributos de este personaje: su memoria y su ingenio, mismos que serán sumamente significativos cuando su voz enuncie el discurso funerario. Las otras dos declaraciones permiten ubicar el desplazamiento físico de Lucas Macías por dos espacios específicos: el de la velación y el del enterramiento, o descanso eterno, de los difuntos.

En la provincia mexicana, el velorio y el cementerio son dos territorios donde la vivencia individual es celebrada como asunto de la colectividad, donde lo individual posibilita las expresiones colectivas de la fe, la fraternidad, la solidaridad y de todas las creencias y representaciones ${ }^{10}$ que conforman el imaginario compartido." Son, también, los espacios simbólicos de la igualdad de circunstancias: nuestro carácter de seres mortales se hace efectivo en ellos. Son parte fundamental de los ritos mortuorios que entretejen rituales diversos como el rezo, el canto, las alabanzas y expresiones de devoción religiosa; pero también entretejen otras prácticas como el repaso detallado de las causas de la muerte y las valoraciones sobre la vida del difunto, convirtiéndose así en eventos de socialización donde el lenguaje tiene un lugar destacado. Animados por el café, el aguardiente, el pulque o cualquiera de las bebidas propias de la región donde ocurren, en los velorios y en los enterramientos se habla tanto del difunto como de sus deudos y se discuten asuntos éticos y filosóficos, cotidianos y trascendentales, asociados a la vida y a la muerte. Dando lugar, así, a la construcción de discursos funerarios eminentemente orales. Uno de estos discursos es recreado artísticamente en la novela de Yáñez en la figura de Lucas Macías.

\section{Resonancias diversas y vínculos dialógicos en el discurso de Lucas}

Iniciemos con el siguiente fragmento en el que resaltan dos asuntos: por un lado, el énfasis que el narrador le imprime a lo que constituye uno de los quehaceres centrales del personaje: hacer el cómputo de los muertos; y, por otro, la manera en la que deja que se escuche la voz de Lucas para que sea él quien comience a enunciar su discurso funerario:

Lucas Macías gusta repasar por este tiempo su registro de quienes han muerto y de las desgracias acaecidas en agosto, por lo menos desde los años de cuarenta y ocho y de cincuenta, que caen dentro de su memoria personal, aunque suele dilatarlos hacia atrás con testimonios ajenos (Yáñez, 1993: 161).

Y, efectivamente, una vez dicho esto, una marca textual nos señala que es la voz de Lucas Macías la que 
comenzamos a escuchar y con ella una diversidad de resonancias sobre el acontecer humano en distintos tiempos y espacios:

Contaba mi padre que la inundación grande que se llevó todo el barrio de las tenerías fue meritamente la noche que hizo luna llena en agosto del veinticinco, mismo año en que dio el sarampión como nunca, y mi padre daba gracias a Dios de que entonces todavía no viniera al mundo porque no hubo familia sin muertito, todos diz que decían que la culpa era del gobernador, el primer gobernador, don Prisciliano Sánchez, que fue de los primeros liberalotes declarados, y en su tiempo vino la masonería, y se hizo guerra a Nuestra Santa Madre; pero no tanto como el treinta y tres, con don Valentín, que quiso robarse los bienes de la iglesia, y allí que se suelta el cólera; nomás en Guadalajara y nomás en agosto murieron más de dos mil cristianos, y hubo días de doscientos y de doscientos cincuenta fallecidos; aquí el pueblo quedó hecho cementerio, de no haber ni quien enterrara a los muertos, pues el cólera no perdonó ni al cura ni a los ministros, que ya para el doce de agosto se habían ido todos al otro mundo: el día que murió el señor cura, que dicen que fue el cuatro de ese mes, murieron treinta y tres gentes, no más de aquí de la localidad, y luego dice que Dios no castiga en esta vida; váyanle haciendo la cuenta de los que murieron ese año en todo el país, si nomás en Guadalajara pasaron de cuatro mil, y aquí en el pueblo no bajaron de quinientos, porque fue de las partes en que pegó más fuerte, yo me acuerdo que ya estaba grande y las gentes se medio morían no más de acordarse de ese año, y más de ese mes de agosto del treinta y tres (Yáñez, 1993: 161).

Antes de analizar qué dice -y cómo lo dice- Lucas Macías, es preciso interrogarnos acerca de una de las declaraciones del narrador: ¿A qué se refirió cuando dijo que "suele dilatarlos hacia atrás con testimonios ajenos"? Se refiere, sin duda, a una de las características de la voz de Lucas: la incorporación en su discurso de diversas y contrastantes voces ${ }^{12}$ por medio de lo cual posibilita el ingreso de testimonios ajenos sobre hechos pasados. Una de esas voces es la del padre ("Contaba mi padre que"), voz sabia y afectiva que no sólo es capaz de brindar información sobre tragedias acaecidas en tiempos remotos, sino de agradecer a Dios que el hijo no hubiera nacido en ese entonces librándose así de experimentarlas ("y mi padre daba gracias a Dios de que entonces todavía no viniera al mundo porque no hubo familia sin muertito"), voz conocedora y entrañable que mediante la oralidad dio testimonio al hijo de, al menos, los siguientes sucesos ocurridos en el año 1825: a) una gran inundación y, b) una epidemia de sarampión. Dentro de la revisión bibliográfica realizada no encontré información sobre ambos sucesos pero es posible que el personaje esté cruzando datos, deslizándose entre acontecimientos y temporalidades diversas, como suele ocurrir en los relatos orales, y que utilice la expresión "la noche que hizo luna llena en agosto del veinticinco" para referirse a la aurora boreal que aconteció en 1859, cuya aparición desató controversias entre liberales y conservadores ${ }^{13}$ a propósito de las leyes de Reforma, ${ }^{14}$ tal interpretación tiene sentido si consideramos que inmediatamente después el personaje hace referencia a cómo la gente culpaba al promotor del federalismo ${ }^{15}$ y primer gobernador liberal del estado de Jalisco: don Prisciliano Sánchez, ${ }^{16}$ de los extraños acontecimientos. Aún así, nos queda pendiente el asunto de la inundación referida: ¿Efectivamente ocurrió, en el tiempo en que triunfaron los liberales, una "inundación grande que se llevó todo el barrio de las tenerías"? Pienso que, si la hubo, debió ser sumamente destructiva como para desaparecer un barrio completo y si el padre de Lucas registró oralmente el suceso, para después narrárselo al hijo, es porque el barrio de las tenerías le resultaba significativo, pero de tal acontecimiento no parece haber registro, a no ser que estemos frente a una alusión metafórica acerca de cómo el triunfo de los liberales se llevó, como si de una gran inundación se tratara, uno de los barrios que simbolizaban al período 
colonial. Digo lo anterior porque, según la información obtenida en la revisión documental, entre los siglos XVIII y XIX la ciudad de Guadalajara estaba dividida por el río San Juan de Dios: al poniente vivía la burguesía local y al oriente se localizaba la población pobre e indígena, que se dedicaba a abastecer a los españoles, ${ }^{17}$ parte de ese abasto consistía en las tenerías, cuyos desperdicios contribuían a la insalubridad del mencionado río, ${ }^{18}$ así que no descarto la posibilidad de que Lucas Macías se esté refiriendo precisamente a la terminación de ese período histórico que se llevó consigo lo más detestable o despreciable de la colonia simbolizado en las tenerías, espacios de insalubridad, pestilencia y pobreza. ${ }^{19}$

Pero veamos qué otros rasgos identificamos. El párrafo citado desborda un tono popular que es subrayado con la incorporación del "diz que": una manera de hacernos saber que se trata de rumores propagados por la gente común, pero también el primero de varios nexos dialógicos con otro fragmento que además da testimonio del tiempo y el espacio de lo que aquí se viene hablando: me refiero a lo expresado por Guillermo Prieto en Memorias de mis tiempos 1828-1840.20 Entre ambos fragmentos es posible identificar, al menos, los siguientes vínculos:

\begin{tabular}{|c|c|}
\hline Lucas Macías & Guillermo Prieto \\
\hline "todos diz que decían" & $\begin{array}{l}\text { "oía como entrecortados } \\
\text { rumores" }\end{array}$ \\
\hline $\begin{array}{l}\text { "fue de los primeros libera- } \\
\text { lotes declarados" }\end{array}$ & $\begin{array}{l}\text { "con algunos eminentes } \\
\text { liberales" }\end{array}$ \\
\hline $\begin{array}{l}\text { “en su tiempo vino la ma- } \\
\text { sonería” }\end{array}$ & $\begin{array}{l}\text { "con su cauda de maso- } \\
\text { nes” }\end{array}$ \\
\hline $\begin{array}{l}\text { "se hizo guerra a Nuestra } \\
\text { Santa Madre" }\end{array}$ & $\begin{array}{l}\text { "pero eso sí, cada uno con } \\
\text { su Virgen de Guadalupe” }\end{array}$ \\
\hline "el treinta y tres" & $\begin{array}{l}\text { "el año horriblemente me- } \\
\text { morable" }\end{array}$ \\
\hline “con don Valentín" & "de Farías" \\
\hline $\begin{array}{l}\text { "quiso robarse los bienes } \\
\text { de la iglesia" }\end{array}$ & "su plan de regeneración" \\
\hline “que se suelta el cólera” & "del Cólera Morbo" \\
\hline
\end{tabular}

Estamos, así, no solamente frente a la recreación artística de un pasaje memorable, por su carácter testimonial sobre el siglo XIX,21 sino también, (y esto resulta sumamente significativo en la configuración del discurso que nos ocupa), frente a una enunciación profundamente popular que, en los inicios del siglo XX, dialoga con un texto escrito en el siglo anterior por un poeta popular como lo fue Guillermo Prieto ${ }^{22}$ y esa enunciación dialógica ${ }^{23}$ la realiza un viejo analfabeta que, no obstante, "se perece [...] porque alguien le lea cuantos libros, revistas y periódicos caen en sus manos y se ingenia en conseguir" (Yáñez, 1993: 79): Lucas Macías. Se hace evidente así, por un lado, la circulación en el ámbito popular de lo escrito por Prieto y, por otro, la conjugación tanto de fuentes orales como escritas en la visión del mundo del personaje.

Esta conjugación es, precisamente, la que le permite narrar no sólo acerca de las muertes acontecidas sino también de las circunstancias históricas, económicas, políticas y sociales en las que éstas ocurrieron, y al hacerlo su voz no revela dramatismo sino tonalidades de humor o burla como cuando se refiere a la epidemia de cólera ${ }^{24}$ y le adjudica la capacidad de desenvolverse por su cuenta ("que se suelta el cólera") o cuando, al referir los alcances trágicos que efectivamente causó tanto en la región ${ }^{25}$ como en el país, ${ }^{26}$ se dirige a sus escuchas motivándolos a que hagan el cómputo de los muertos ("váyanle haciendo la cuenta de los que murieron ese año en todo el país, si nomás en Guadalajara pasaron de cuatro mil"), cómputo que resulta muy cercano al señalado en la documentación sobre el tema pero que parece magnificado por el uso insistente del "nomás" ("nomás en Guadalajara y nomás en agosto murieron más de dos mil cristianos, y hubo días de doscientos y de doscientos cincuenta fallecidos") que, por otra parte, acentúa el carácter popular de la narración. El discurso funerario de Lucas Macías deja ver otro aspecto de su concepción del mundo: la igualdad de condiciones a la que nos somete una tragedia; accedemos a ella cuando, con matices de burla, se refiere al cura y los ministros que no contaron con la gracia de la inmunidad y tam- 
bién se fueron al otro mundo: ("aquí el pueblo quedó hecho cementerio, de no haber ni quien enterrara a los muertos, pues el cólera no perdonó ni al cura ni a los ministros, que ya para el doce de agosto se habían ido todos al otro mundo: el día que murió el señor cura, que dicen que fue el cuatro de ese mes, murieron treinta y tres gentes, no más de aquí de la localidad, y luego dice que Dios no castiga en esta vida"). Las tonalidades de humor son subrayadas al incorporar el contexto político en el que se produjo la famosa epidemia: el surgimiento del liberalismo ("todos diz que decían que la culpa era del gobernador, el primer gobernador, don Prisciliano Sánchez, que fue de los primeros liberalotes declarados") y la masonería ("y en su tiempo vino la masonería, y se hizo guerra a Nuestra Santa Madre; pero no tanto como el treinta y tres, con don Valentín, que quiso robarse los bienes de la iglesia").

\section{Memoria e ingenio en el discurso de Lucas}

Recordemos que, tal como lo anuncia el narrador, Lucas Macías no es el más viejo pero entre los longevos que abundan en el pueblo es el de mejor memoria e ingenio. Ello significa que, además de ser capaz de narrar muertes ocurridas en tiempos distantes y de las que se enteró por tradición oral, como lo acabamos de ver, también ha ido afinando su habilidad para testimoniar sobre aquellas muertes ocurridas en temporalidades más cercanas y de las que fue testigo presencial o asistente en las ceremonias fúnebres asociadas a ellas. Todo ello ha propiciado que gane fama como un destacado narrador de los rituales mortuorios acontecidos en el pueblo, tal como lo revela el tono desenfadado y casi festivo con el que una voz anónima lo interroga al respecto: "- ¿Y en agosto de qué año te has echado más velorios, Lucas?" (Yáñez, 1993: 161). Con el mismo tono, como si no estuviera refiriéndose a decesos, Lucas Macías responde mediante un pormenorizado cómputo de los que murieron en el año en que se echó más velorios, según la expresión utilizada por la voz anónima:
El noventa y nueve. Ora va a hacer diez años. Ustedes se han de acordar del difunto Celedonio Ramírez, que lo mataron en bola los Legaspi diz que porque andaba pretendiendo a su hermana Patricia; no pasaron ocho días sin que cayera Juan Legaspi a manos de Apolonio Ramírez, que vengó a su tío Cele; luego fue la madre de los Legaspi, a los dos días, unos dicen que del corazón, otros que de un derrame de bilis. El quince cayó de la torre y lo recogieron muerto, el difunto Jacobo Partida, muy buen albañil y hombre muy de su casa: dejó nueve de familia, con la viuda, doña Chole, que ora viven allá en Cañadas (Yáñez, 1993: 161)

El discurso funerario de Lucas, eminentemente popular, según se advierte por el uso de expresiones que portan este carácter ("Ora" / "diz que"), se orienta siempre a sus escuchas a quienes convoca al recuerdo ("Ustedes se han de acordar"), a que repasen juntos acontecimientos diversos como los trágicos enfrentamientos entre los integrantes de las familias Ramírez y Legaspi por un asunto de celos ("Celedonio Ramírez, que lo mataron en bola los Legaspi diz que porque andaba pretendiendo a su hermana Patricia; no pasaron ocho días sin que cayera Juan Legaspi a manos de Apolonio Ramírez, que vengó a su tío Cele"), o la muerte de la madre de éstos, cuyas causas bien a bien no se conocen aunque distintas versiones circulen de boca en boca ("unos dicen que del corazón, otros que de un derrame de bilis") y, contrapone todos estos hechos, que quedan como asuntos menores, al incorporar en su relato la fecha exacta en que se produjo otro deceso ("El quince cayó de la torre y lo recogieron muerto, el difunto Jacobo Partida") y al expresar valoraciones sobre el difunto, sobre la actividad que realizaba y sobre la situación de sus deudos ("muy buen albañil y hombre muy de su casa: dejó nueve de familia, con la viuda, doña Chole, que ora viven allá en Cañadas").

Es así que, a partir del día quince, su relato, que cubre todo el mes de agosto del año $1899,{ }^{27}$ se va deteniendo en un registro casi cotidiano. Veamos: 
El día de San Bartolomé iah, qué día! ustedes se acuerdan, murieron don Victoriano Rábago, ése sí de derrame de bilis porque en lo que iba del mes la peste no le había dejado ya ni una cabeza de ganado: el día que murió le habían llevado la noticia de que los dos últimos bueyes habían azotado como de rayo; también murió ese día, casi repentinamente, doña Celsa Toledo, la hermana de don Anselmo, dicen que de disgustos con su cuñada; el tercer muerto fue un hijo de Mauricio Reyes, que lo mató un caballo; todavía no enterraban a ninguno de los tres, cuando trajeron el cuerpo de Alberto, que le decían por mal nombre la Cartuchera, y lo mató un rayo, yendo para el rancho de Pastores (Yáñez, 9.5: 161-162).

Lo primero que merece destacarse es la mención de un día específico del santoral católico ("El día de San Bartolomé"), así como la expresión que le sigue ("iah, qué día!") con las cuales valora la cualidad de un día lleno de calamidades. Según las creencias populares, ese día — también llamado de San Bartolo- el diablo anda suelto y comete todo tipo de fechorías y desmanes. Este rasgo, de igual forma identificado en otra novela colmada de enunciaciones populares ${ }^{28}$ acentúa el carácter popular tanto del discurso de Lucas Macías como de la novela. Bajo tal consideración, todas las muertes ocurridas este día son, en realidad, resultado de dichos desmanes y como tales son registradas por Lucas Macías, por ello su voz revela un cierto matiz de burla y humor cuando incluye a doña Celsa y a los bueyes en su comentario sobre la manera repentina y fulminante en que murieron ("habían azotado como de rayo / también murió ese día, casi repentinamente"), burla y humor que también se advierte al explicar las defunciones de los hermanos por los disgustos causados, en un caso, por los bueyes y, en otro, por la cuñada ("ése sí de derrame de bilis / dicen que de disgustos con su cuñada"). La tercera fechoría es la intervención de un caballo que mata, casi igual que los Legaspi y los Ramírez: ("el tercer muerto fue un hijo de Mauricio Reyes, que lo mató un caballo") y la cuarta es la muerte de un hombre cuyo apodo denota cierto carácter violento y, quizá por ello, es referida con cierto desapego y burla porque, al ser un rayo la causa de la repentina muerte, uno casi lo puede ver azotando en el suelo como los bueyes ("el cuerpo de Alberto, que le decían por mal nombre la Cartuchera, y lo mató un rayo, yendo para el rancho de Pastores").

A partir del siguiente párrafo ese tono de burla y humor se intensifica para dar registro puntual de los demás fallecimientos:

Ese año murieron de viejos, casi sin enfermedad, casi sin guardar cama, por unas deposicioncillas, don Chencho Gutiérrez, don Pascasio Aguirre, doña Candidita Soto y don Isidro Cortés. Hubo sus angelitos: un hijo de don Secundino Torres, otro recién nacido de Valente Mercado y una muchachita del difunto Zacarias el Mocho. Elúltimo día fue cuando murió de pulmonía el Padre don Arcadio Prieto: ése sí fue velorio, con lo que el pueblo lo quería, que aun decían que iban a pedirlo de cura, iy el entierro? Ustedes se acuerdan. Yo no he visto otro tan en grande (Yáñez, 1993: 162).

La insistencia en la edad de los difuntos parece derivarse de una concepción acerca de la muerte como una circunstancia inevitable que no hace distingos y se lleva lo mismo a viejos, niños, jóvenes o personas cuyo oficio las mantiene más cerca de Dios como es el caso del sacerdote. Y las causas suelen ser tan diversas que van, como hemos visto, desde el asesinato, una caída inesperada, una falla del corazón, un rayo, hasta unas deposicioncillas, tal como afirma el personaje, con evidente sentido del humor, cuando menciona los decesos de los más viejos del pueblo ("murieron de viejos, casi sin enfermedad, casi sin guardar cama, por unas deposicioncillas, don Chencho Gutiérrez, don Pascasio Aguirre, doña Candidita Soto y don Isidro Cortés"). Los niños fallecidos no alcanzaron siquiera a tener nombre y son mencionados como angelitos y como hijos del nombre de su padre ("Hubo sus angelitos: un 
hijo de don Secundino Torres, otro recién nacido de Valente Mercado"), que es a quien la comunidad conoce, o conoció, incluido el apodo que llevó en vida ("y una muchachita del difunto Zacarías el Mocho").

\section{Los muertos en la memoria o la dimensión ética en el discurso de Lucas}

Asistir a los eventos fúnebres no tendría ningún sentido si en ellos no se repasara la memoria de cómo reaccionó el pueblo ante determinadas muertes, incluyendo lo que se dijo acerca del cómo y del por qué de tales muertes. Lucas Macías parece cifrar su discurso funerario en el anterior planteamiento y por ello rememora lo acontecido con detalles que se vuelven evidencias de acciones dolosas y testimonio definitivo de injusticias cometidas por los poderosos, tal como ocurre en el extenso párrafo que cito a continuación:

— ¿Ni siquiera el entierro de los Medina? ¿Cuándo fue que los mataron? -En agosto del setenta y siete. Un lunes. Don Lino Villegas había entrado de autoridad al principio de año [...] un domingo aparecieron los de la gendarmería, ya casi en la noche, y como a las ocho cayeron en la casa donde estaban los Medina; iban encabezados por don Lino, que pidió a don Trinidad que se diera preso con sus dos hijos; Medina contestó que ellos eran hombres de paz y que no había motivos para que los apresaran; don Lino les contestó que ya sabía el gobierno que querían levantarse en armas [...] protestó don Trinidad que era falso y mentiroso, que fuera hombre para no buscar pretextos, queriéndolos perjudicar, que si tenía motivos personales le hablara en lo cortito y a solas [...] don Lino azuzó a la gente para echar abajo las puertas, comenzaron los tiros [...] los soldados mataron a boca de jarro a don Trinidad y a sus hijos don Justo y Policarpio; dicen que don Lino también les disparó sobre caídos, y luego, enfureció contra la gente que se arremolinaba llorando, queriendo ver los cuerpos, diciendo que los Medina eran inocentes, trató de dispersarla enfocándoles las carabinas; fue un día muy triste, nublado; parece que se hubiera muerto el padre del pueblo; los pobres que habían recibido beneficios de don Trinidad y de sus hijos no se apartaron de los cuerpos que estaban tendidos en unas cruces de ceniza; fue mucha gente al entierro, a pesar de las amenazas de don Lino; pero yo digo que el entierro del Padre Prieto fue mejor, porque en el otro, la rabia y el miedo de las gentes, digo yo, como que le quitaban solemnidad, y en cambio el del Padre parecía una procesión en grande, muy solemne. Pero los dos entierros en su tanto, son de los que no se olvidan (Yáñez, 1993: 162-163)

El discurso funerario de Lucas Macías se va construyendo mediante una esmerada articulación entre personajes, sucesos y diversas prácticas colectivas. Va incorporando en la memoria compartida a los muertos para que sigan estando, para que no se olviden y con precisión del día y la hora, de los movimientos realizados, de las palabras dichas, de los sentimientos compartidos, logra el enaltecimiento de unos y la degradación de otros: su palabra va construyendo así epitafios orales que reseñan vida y obra de quienes merecen ser recordados por la colectividad.

En el universo de Alfilo del agua, el responsable de dar santo y seña de aquellos que han muerto, incluyendo tanto información como valoración de los actos realizados en vida, es Lucas Macías:

— iCaray, cómo es la vida! Quién había de decirle al famoso Espiridión Ramos [...] quién había de decirle que lo desenterrarían para que en el mismo agujero en que se pudrió, sepultaran a don Timoteo Limón, que como ustedes han de saber, fue hijo de don Arcadio, mismo a quien Espiridión, después de matarlo, quería que no lo enterraran, y porfió hasta que el cuerpo apestaba, y los vecinos tuvieron que ofrecer dinero al chinaco (dos mil pesos contantes y sonantes) a fin de que diera el permiso para el entierro; iquién puede saber ora cuáles son los huesos que quedaron del guerrillero mala entraña? Y 
luego acá: miren ustedes, quedaron pies con pies Micaela y la dichosa Teo Parga, que diz que hace milagros. ¿Qué cosas tiene la vida! (Yáñez, 1993: 191).

Y lo hace, por un lado, convocando a los demás a que recuerden, a que tengan en la memoria la suma de los actos de los muertos, a que no olviden ni agravios ni injusticias cometidos por poderosos que en el camposanto comparten la misma circunstancia y una misma tumba en donde sus huesos se confunden, ${ }^{29}$ por otro lado, vinculando personajes opuestos como lo son una mujer acusada de casquivana y otra considerada santa y virtuosa. El repaso que Lucas Macías va haciendo mientras recorre el cementerio revela una burla orientada hacia los poderosos, hacia sus valores y afanes de distinción económica, política y religiosa.

Para concluir, sólo quiero subrayar que el discurso funerario de Lucas Macías abarca la dimensión ética del acontecer humano $0^{30}$ en tanto que expresa su visión sobre cómo las relaciones que los humanos establecemos y los actos que realizamos en vida definen, de algún modo, la calidad de nuestra muerte. El humor y la burla se filtran en sus expresiones valorativas sobre la vida y la obra de quienes aparecen juntos en el camposanto, revelando así conflictos y contradicciones morales que caracterizan al pueblo de la novela de Yáñez. Detrás de su decir hay una concepción lúdica y festiva del mundo, una particular manera de entender la vida y la muerte, de nombrar a los muertos desenmascarando sus acciones. Su discurso funerario subvierte, así, el orden establecido desde el poder de las instituciones: la del poder político y la del poder religioso que han marcado por siempre el ritmo de ese "pueblo solemne". ${ }^{31}$

\section{Notas}

${ }^{1}$ Agustín Yáñez, Al filo del agua, Arturo Azuela coordinador, México, Consejo Nacional para la Cultura y las Artes/Unesco, México, 1993, (Colección Archivos; 22), edición crítica, que en adelante citaré como Al filo del agua y la página correspondiente.
2 Norma Esther García Meza, Al filo del agua. Voces y memoria, colección Manuel Sánchez Mármol, Narrativa y Estudios literarios, Universidad Juárez Autónoma de Tabasco, México, 200l, que en adelante citaré como Al filo del agua. Voces y memoria y la página correspondiente. Para lo correspondiente al contexto literario e histórico de la publicación de Al filo del agua, ver: Norma Esther García Meza, "Representación artística de la tensión entre el mundo popular y el mundo oficial del porfiriato en Al filo del agua", en Revista electrónica de estudios literarios Espéculo, vol. 40, noviembre 2008-febrero 2009, en http://www.ucm.es/info/especulo/

${ }^{3}$ Al filo del agua. Voces y memoria, pp. 122-148.

${ }^{4}$ Ibid, p. 137.

${ }^{5}$ En la novela de Yáñez es posible identificar, al menos, otros dos discursos funerarios, el enunciado por Luis Gonzaga y el del narrador. Ver Al filo del agua, pp. 74142-143.

6 "No es el más viejo -abundan longevos en el pueblo-; pero entre los viejos es el de mejor memoria y más vivo ingenio. Registro civil y público de personas, familias, cosas y contratos. Algo zahorí, «no por diablo -como él dice-, sino por viejo». Un poco leguleyo y por igual- médico desinteresadamente. No sabe leer, se perece, sin embargo, porque alguien le lea cuantos libros, revistas y periódicos caen en sus manos y se ingenia en conseguir, empeñoso. Si tuviera recursos, lo primero, tomaría un lector a su servicio, que fuera incansable. Ha ido acuñando así su filosofía o, más bien, destilándola en experiencia y lecturas, para que luego no falte al recordar una fecha, un antecedente, al aconsejar un remedio, un recurso legal o cuando pronostica. «Filósofo de velorio» suelen llamarlo burlándosele, pues que no falta a ninguno y allí rompe la vena de sus consideraciones y máximas. Cronista fiel, carece de historia personal; en la vida sólo ha sido espectador y notario de acaecimientos ajenos; de sí no sabe ni la edad, más que por aproximación: seguramente pasa de los ochenta, porque ya se acuerda bien de cuando su padre, que era soldado, fue a la guerra de Tejas y 
también a la de los Pasteles, donde le cortaron la pata a don Antonio, tan familiar en boca de Lucas Macías [...]", Ibid, p. 79.

${ }^{7}$ Ibidem.

${ }^{8}$ Ibidem

${ }^{9}$ Ibid, p. 191.

10 Las representaciones sociales son construcciones simbólicas creadas y recreadas en los procesos de interacción social y, según Serge Moscovici, son "una modalidad particular del conocimiento, cuya función es la elaboración de los comportamientos y la comunicación entre los individuos. La representación es un corpus organizado de conocimientos y una de las actividades psíquicas gracias a las cuales los hombres hacen inteligible la realidad física y social, se integran a un grupo o en una relación cotidiana de intercambios, liberan los poderes de su imaginación”, Serge Moscovici, El psicoanálisis, su imagen y su público, Huemul, Buenos Aires, Argentina, 1979, pp. 17-18.

11 " [...] los imaginarios sociales son referencias específicas en el vasto sistema simbólico que produce toda colectividad y a través de la cual se percibe, se divide y elabora sus finalidades. De este modo, a través de estos imaginarios sociales, una colectividad designa su identidad elaborando una representación de sí misma; marca la distribución de los papeles y las posiciones sociales, expresa e impone ciertas creencias comunes, fijando especialmente modelos formadores [...] una de las funciones de los imaginarios sociales consiste en la organización y el dominio del tiempo colectivo sobre el plano simbólico. Intervienen activamente en la memoria colectiva para la cual [...] a menudo los acontecimientos cuentan menos que las representaciones imaginarias a las que ellos mismos dan origen y encuadran [...] Los imaginarios sociales y los símbolos sobre los cuales se apoyan los primeros forman parte de los complejos y compuestos sistemas, a saber, en especial los mitos, las utopías y las ideologías", B. Baczko, Los imaginarios sociales. Memorias y esperanzas colectivas, Buenos Aires, Argentina, Nueva Visión, 1991, pp. 28-30.
12 "La novela es la diversidad social, organizada artísticamente, del lenguaje; y a veces, de lenguas y voces individuales [] a través de ese plurilingüismo social y del plurifonismo individual, que tiene su origen en sí mismo, orquesta la novela todos sus temas, todo su universo semántico-concreto representado y expresado. El discurso del autor y del narrador, los géneros intercalados, los lenguajes de los personajes, no son sino unidades compositivas fundamentales, por medio de las cuales penetra el plurilingüismo en la novela; cada una de esas unidades admite una diversidad de voces sociales y una diversidad de relaciones, así como correlaciones entre ellas (siempre dialogizadas, en una u otra medida) []", M. Bajtín, Teoría y estética de la novela. Trabajos de investigación, Trad., Helena Kriúkova y Vicente Cazcarra, Taurus, Madrid, 1989, p. 81, que en adelante citaré como Teoría y estética de la novela y la página correspondiente.

13 "La aparición de la aurora boreal, en 1859, por ejemplo, fue para los liberales un fenómeno físico, en cambio, los conservadores la interpretaron como un castigo divino, ocasionado por el cierre de conventos ordenado por las leyes de Reforma", Arturo Camacho Becerra, Álbum del tiempo perdido. Pintura jalisciense del siglo XIX, Zapopan FONCA-El Colegio de Jalisco, México, 1997, p. 82.

${ }^{14} \mathrm{Al}$ respecto resulta interesante lo expuesto en el siguiente fragmento: "El año del cólera fue como se denominó a 1833, año en que ocurrió la espantosa pandemia; vino acompañada de una serie de avisos como por ejemplo: 'tal la aurora boreal que en 1833 enrojeció el cielo e hizo a los ingenuos temer el castigo de Dios por las reformas de Don Valentín Gómez Farias, como parecía confirmarlo la epidemia de cólera que las acompañó"', Bernardo Martínez Ortega, "El cólera en México durante el siglo XIX", en Revista Ciencias, Universidad Nacional Autónoma de México, No. 25, Enero 1992, pp. 38-39. Ver también lo expuesto por Josefina Zoraida Vázquez: "Tal la aurora boreal que, en 1833, enrojeció el cielo e hizo a los ingenuos temer el castigo de Dios por las reformas de Don Valentín Gómez Farías, como parecía 
confirmarlo la epidemia de cólera que las acompañó", Josefina Zoraida Vázquez, "Los primeros tropiezos", en Historia general de México, tomo II, México, El Colegio de México, México, 1986, p. 799.

15 "El federalismo [...] significó la consolidación de la independencia mexicana al conferir libertad y autogobierno, no sólo al gobierno colonial de la ciudad de México, sino a las partes más afectadas del país por el coloniaje, las provincias mismas [...] el federalismo determinó las características del sistema presidencial a partir de la constitución de 1824 [...] en México el sistema fue promovido por ayuntamientos y provincias que buscaban implantar el autogobierno y liberarse de un centro político [...] La separación entre la Iglesia y el Estado fue discutida en Jalisco antes que en parte alguna del país [...] El aspecto más conflictivo fue originado por la segunda parte del artículo [...] relativo al Patronato del Estado sobre cuestiones de administración. La jerarquía Eclesiástica de Guadalajara y del resto del país consideraron que la disposición de Jalisco era incompatible con los artículos $3^{\circ}$. y 50 , fracción XII, de la Constitución Federal de 1824 (se quería argumentar, en el mejor de los casos, que correspondía a la Federación y no a los estados, la regulación de los gastos para la conservación del culto; pero en el fondo, esta polémica representó el primer enfrentamiento entre el pensamiento liberal y la Iglesia católica del país [...] La polémica concluyó, y los clérigos jaliscienses juraron la Constitución cuando fue expedido el decreto número 124 del Congreso Federal Constituyente, fechado el 2 de diciembre de 1824, suscrito por Valentín Gómez Farías, José Ma. Izazaga y José Rafael Alarid [...]", Manuel González Oropeza, El federalismo, UNAM, México, 1995, pp. 11-12-59-61.

16 “[...] Prisciliano Sánchez, después de haber guiado todas las actividades del Congreso constituyente del estado, fue electo como primer gobernador del nuevo régimen constitucional el 8 de enero de 1825", Ibid, p. 64. En las notas explicativas de la edición crítica de Al filo del agua se afirma lo siguiente: "Presciliano Sánchez (1783-1826).
Gobernador liberal de Jalisco. Despojó al clero del control de la educación superior en Guadalajara. Creó un nuevo instituto de ciencias. Una de las iniciativas del incipiente liberalismo mexicano fue la fundación de los institutos de ciencias y artes, que desempeñaron el papel de escuelas superiores para las necesidades de sus respectivos estados. Fue un paso trascendental porque con ellos el liberalismo se forjó un instrumento educativo eficaz en la lucha contra la universidad y los seminarios dominados por el clero y los conservadores. Es significativo que de aquellos institutos salieran los grandes representantes de la Reforma", Al filo del agua, nota 59, p. 247.

17 "Durante los siglos XVIII y XIX, el río cortaba la ciudad en dos: al poniente había quedado el centro histórico, alrededor del cual vivía la burguesía local formada, en general, por una población criolla, y en sus márgenes se encontraban los barios de Mezquitán y Mexicaltzingo. Y al oriente se confinaba la Guadalajara indígena y pobre: la clase trabajadora que abastecía a los españoles. Durante siglos, el río fue lugar de recreo y paseo de su alta burguesía; pero durante la Colonia y hasta el siglo XIX, la ciudad se vio azotada en varias ocasiones por el cólera, y el río San Juan de Dios era una fuente insalubre que contribuía a la mortalidad de la población [...]”, Jorge E. Aceves, René de la Torre y Patricia Safa, "Fragmentos urbanos de una misma ciudad: Guadalajara", en Revista Espiral, Estudios sobre estado y Sociedad, vol. XI, núm. 31, septiembre-diciembre de 2004, p.286.

18 "Las tenerías y los talleres situados cerca de sus márgenes seguramente contribuían de manera significativa con la insalubridad que caracterizaba al río en dicho periodo", Ver Guillermo de la Peña, "Ensayos sobre el sur de Jalisco", Cuadernos de la Casa Chata, No. 4, Centro de Investigaciones Superiores del INAH, México, 1980, pp. 12-14.

${ }^{19}$ Resulta interesante el texto que cito a continuación, no sólo por su contenido sino también por la extensa bibliografía que nos ofrece sobre estos temas: María del Carmen León García, "Espacio, olor y salubridad en Toluca al final del Siglo XVIII", en Revista Historia Mexicana, El Colegio de México, vol. LII, núm. 1, 2002, pp. 163-199. 
20 "Era el año horriblemente memorable del Cólera Mor bo [...] Respecto á la cosa pública, que era por entonces lo menos de mi cuidado, oía como entrecortados rumores los nombres de Santa-Anna y de Farías que ocupaban alternativamente el poder, como dos empresarios de compañías teatrales, el uno con su comitiva de soldados baladrones é ignorantes, tahures y agiotistas desaliñados, y el otro con algunos eminentes liberales; pero con su cauda de masones, de patrioteros anárquicos y de gente de acción que era un hormiguero de demonios; pero eso sí, cada uno con su Virgen de Guadalupe y su plan de regeneración entre cuero y carne", (las negritas son mías y cada fragmento marcado se utiliza en el cuadro para ilustrar las relaciones dialógicas), Guillermo Prieto (2006), Memorias de mis tiempos 1828-1840, Ed. facsímil, Alicante: Biblioteca Virtual Miguel de Cervantes, pp. 88-94. Reproducción digital de la edición de París; México: Vda. De C. Bouret, 1906, en http://www.cervantesvirtual.com [10 de julio de 2008]. 21 "Guillermo Prieto (1818-1897). Nace en la ciudad de México [...] Orador, periodista y maestro, es una de las personalidades más brillantes del movimiento de Reforma, que siempre defendió de palabra y de hecho [...] Su labor como periodista se inicia en el año 1837 y continúa a lo largo de toda su vida. Sus primeros textos aparecen en El Mosaico Mexicano; posteriormente colabora con numerosas publicaciones de toda índole: revistas y periódicos de política, de variedades, de literatura. Sin embargo, sus trabajos más frecuentes fueron escritos para El Monitor Republicano y El Siglo XIX. El 2 de marzo de 1897 murió en Tacubaya. Periodista, político, escritor; hombre, en fin, de actividades múltiples, 'lleva en su propia historia la del agitado siglo XIX', según palabras de María del Carmen Millán. Guillermo Prieto es, para la historia de nuestra literatura, un poeta popular, así como un escritor de cuadros costumbristas, de hecho, el primero que se da en México. Simpatizó siempre con los románticos y cultivó las técnicas y los ambientes de esa tendencia. Fundador de la Academia de Letrán, gran parte de su obra literaria está dispersa en los periódicos y las revistas de su época [...]", David Huerta, Cuentos románticos, UNAM, México, 1973, pp. 97-98. "Fue más que cronista porque sus cuadros literarios, independientemente de su carácter romántico, son expresiones vivas de un pueblo que palpita en medio de pasiones amorosas, de pasiones literarias, de pasiones políticas. Las Memorias de mis tiempos, de Guillermo Prieto [...] son precisamente eso: expresión íntima, naturaleza y esencia de un México que nace y al que Prieto ama y acompaña durante casi un siglo (1818-1897)", María de Lourdes Franco, Literatura Hispanoamericana, Limusa, México, 1989, p. 163.

22 "Las imágenes de los personajes populares de la ciudad de México son descritas por Prieto en sus poemas y cuentos, reconocidos como parte importante de la obra producida por la segunda generación de románticos [...] Julio Jiménez Rueda lo ubica entre 'los poetas de inspiración popular, [el que] va a la plazuela, oye hablar al pelado, al lépero, le encanta la china, [y] le subyuga el toque pintoresco, la alusión intencionada, la palabra o el giro vernáculo", Leonor Ludlow, "Guillermo Prieto”, Belem Clark y Elisa Guerra, (Coord.), La república de las letras: asomos a la cultura escrita del México decimonónico, UNAM, México, 2005, p. 194.

23 "[...] toda palabra concreta (enunciado), encuentra siempre un objeto hacia el que orientarse, condicionado ya, contestado, evaluado, envuelto en una bruma que lo enmascara; o, por el contrario, inmerso en la luz de las palabras ajenas que se han dicho acerca de él. El objeto está rodeado e impregnado de ideas generales, de puntos de vista, de valoraciones y acentos ajenos. La palabra orientada hacia su objeto entra en ese medio agitado y tenso, desde el punto de vista dialógico, de las palabras, de las valoraciones y de los acentos ajenos; se entrelaza en complejas relaciones, se une a algunos, rechaza a otros, o se entrecruza con los demás; todo eso modela sustancialmente la palabra, que puede sedimentarse en todos sus estratos semánticos, complicar su expresión, influenciar por completo su aspecto estilístico", Teoría y estética de la novela, p. 94. 
24 "En la segunda mitad de 1833, la prensa anunció su arribo por dos puntos: en el noroeste, procedente de Nueva Orleáns entró en Tamaulipas por el puerto de Tampico, donde se declaró la epidemia el 24 de junio. Avanzó por Coahuila hacia el centro y occidente de México, siguiendo la ruta de la plata [...] La epidemia de cólera, en 1833, marca un parteaguas en aspectos de salud pública, al haber llamado la atención de las autoridades y de los individuos hacia la pobreza, la falta de higiene, la insalubridad [...] y la carencia de medios para atender a la población de escasos recursos [...]", Lourdes Márquez Morfín, La desigualdad ante la muerte en la ciudad de México: el tifo y el cólera, Siglo XXI editores, México, 1994, pp. 271-280.

25 "La epidemia duró en Guadalajara dos meses; en los siguientes tres meses, se presentaron casos aislados. Murieron 3275 personas; entre el 8 y el 20 de agosto, se enterró a un promedio de 150 víctimas diarias", Lilia V. Oliver, Un verano mortal: Análisis demográfico y social de una epidemia de cólera, Gobierno del Estado de Jalisco, México, 1986, pp. 31-32.

${ }^{26}$ Según Elsa Malvido, en el año de 1833 el cólera provocó la muerte de 14,000 personas en la ciudad de México y de 3,275 en la ciudad de Guadalajara. Ver Elsa Malvido, La población. Siglos XVI al XX, UNAM, México, 2006, p. 155. La única referencia que encontramos respecto a los estragos del cólera en zonas rurales de Jalisco es la que citamos a continuación: "El 31 de enero. Se anuncia que en Chiapas, aparece la epidemia del Cólera Morbus, llega a Zapotlán El Grande el 17 de agosto del mismo año. Para el 30 de septiembre ya habían muerto mil cien personas entre niños, jóvenes y ancianos". Fuente: http// www.e-local.gob.mx (consultada: 12 de julio de 2008).

${ }^{27} \mathrm{Al}$ respecto, recordemos lo siguiente: "La novela reconstruye el espacio de la provincia mexicana, aunque los acontecimientos narrados rebasen este ámbito y abarquen sucesos que se estaban dando en buena parte del territorio mexicano. Temporalmente abarca un periodo que va de marzo de 1909 a noviembre de 1910. Periodo que es posible precisar por algunos indicios identificados en la voz narradora", Al filo del agua. Voces y memoria, p. 100. ${ }^{28}$ Me refiero a La feria de Arreola. Ver Norma Esther Gar- cía Meza, Tesis doctoral Fiesta y memoria antigua. Voces y visiones del mundo en la obra de Arreola, Programa de Posgrado en Letras, Facultad de Filosofía y Letras, UNAM, Agosto de 2006, pp. 73 y 136. Ver también Juan José Arreola, La feria, Joaquín Mortiz, México, 2002.

${ }^{29}$ El enterramiento caótico, según afirma Martina Will, fue una práctica frecuente hacia finales del siglo XVIII "Una tumba podía albergar literalmente una docena de cuerpos, con los huesos [...] entremezclados indiscriminadamente", Martina Will, "De cuerpo a cadáver", La muerte: representaciones sociales mexicanas, Relaciones, núm. 94, vol. XXIV, primavera, El colegio de Michoacán, México, 2003, p. 77.

${ }^{30}$ Desde la perspectiva filosófica de M. Bajtín, la actividad que desarrollamos como seres humanos está “[...] concebida siempre en una estrecha relación con el otro. Así, cada quehacer nuestro tendrá el carácter de un encuentro con el otro basado en una responsabilidad específica que la relación con el otro genera: debido a mi posición única e irrepetible en el espacio y el tiempo, yo soy la única persona capaz de realizar mis actos concretos que repercuten de una manera concluyente en el otro [...] Cualquier acto nuestro, cuando no es fortuito, sino que obedece a la tensión permanente del deber ser que proviene de la presencia del otro, es un acto entendido específicamente como 'acto ético' [...] un proceder que contrae responsabilidades y consecuencias: 'en el ser no hay coartada', dice Bajtín", M. Bajtín, Yo también soy (fragmentos sobre el otro), Tatiana Bubnova (selección, traducción, comentarios y prólogo), Taurus, Colección La huella del otro, México, 2000, pp. 17-18.

${ }^{31}$ Al filo del agua, p. 6.

\section{Bibliografía}

Aceves, Jorge E., René de la Torre, y Patricia Safa (2004), "Fragmentos urbanos de una misma ciudad: Guadalajara”, en Revista Espiral, Estudios sobre estado y Sociedad, vol. XI, núm. 31, México: Universidad de Guadalajara, septiembre-diciembre, pp. 286-296. 
Arreola, Juan José (2002), Laferia, México: Joaquín Mortiz. Bajtín, M. (1989), Teoría y Estética de la Novela. Trabajos de Investigación, Trad., Helena Kriúkova y Vicente Cazcarra, Madrid: Taurus..

Bajtín, M. (2000), Yo también soy (fragmentos sobre el otro), Tatiana Bubnova (selección, traducción, comentarios y prólogo), México: Taurus, Colecc. La huella del otro.

Baczko, B. (1991), Los imaginarios sociales. Memorias y esperanzas colectivas, Buenos Aires, Argentina: Nueva Visión.

Camacho Becerra, Arturo (1997), Álbum del tiempo perdido. Pintura jalisciense del siglo XIX, Zapopan, Jalisco, México: FONCA-El Colegio de Jalisco.

De la Peña, Guillermo (1980), "Ensayos sobre el sur de Jalisco", en Cuadernos de la Casa Chata, núm. 4, México: Centro de Investigaciones Superiores del INAH, pp. 12-14.

Franco, María de Lourdes (1989), Literatura Hispanoamericana, México: Limusa.

García Meza, Norma Esther (2001), Al filo del agua. Voces y memoria, México: colección Manuel Sánchez Mármol, Narrativa y Estudios literarios, Universidad Juárez Autónoma de Tabasco.

García Meza, Norma Esther (2006), Fiesta y memoria antigua. Voces y visiones del mundo en la obra de Arreola, Tesis doctoral, México: Programa de Posgrado en Letras, Facultad de Filosofía y Letras, UNAM.

García Meza, Norma Esther (2008), "Representación artística de la tensión entre el mundo popular y el mundo oficial del porfiriato en Al filo del agua", en Revista electrónica de estudios literarios Espéculo, vol. 40, 〈http://www.ucm.es/info/especulo/〉 [noviembre 2008-febrero 2009].

González Oropeza, Manuel (1995), El federalismo, México: UNAM.

Huerta, David (1973), Cuentos románticos, México: UNAM. León García, María del Carmen (2002), "Espacio, olor y salubridad en Toluca al final del Siglo XVIII", en Revista Historia Mexicana, vol. LII, núm. 1, México: El Colegio de México, pp. 163-199.
Ludlow, Leonor (2005), "Guillermo Prieto", en Belem Clark y Elisa Speckman, (coord.), La república de las letras: asomos a la cultura escrita del México decimonónico, vol. III, México: UNAM, pp. 189-204.

Malvido, Elsa (2006), La población. Siglos XVI al XX, México: UNAM.

Márquez Morfín, Lourdes (1994), La desigualdad ante la muerte en la ciudad de México: el tifo y el cólera, México: Siglo XXI editores.

Martínez Ortega, Bernardo (1992) "El cólera en México durante el siglo XIX", en Revista Ciencias, núm. 25, enero, México: Universidad Nacional Autónoma de México, pp. 38-39.

Moscovici, Serge (1979), El psicoanálisis, su imagen y su público, Buenos Aires, Argentina: Huemul.

Oliver, Lilia V. (1986), Un verano mortal: Análisis demográfico y social de una epidemia de cólera, Guadalajara, México: Gobierno del Estado de Jalisco.

Vázquez, Josefina Zoraida (1986) "Los primeros tropiezos”, en Historia General de México, tomo II, México: El Colegio de México, pp. 720-799.

Will, Martina (2003), "De cuerpo a cadáver", en La muerte: representaciones sociales mexicanas, Relaciones, núm. 94, vol. XXIV, primavera, México: El Colegio de Michoacán.

Yáñez, Agustín (1993), Al filo del agua, Arturo Azuela (coord.), Colección Archivos; 22, edición crítica, México: Consejo Nacional para la Cultura y las Artes/Unesco.

\section{Sitios de Internet}

Biblioteca Virtual Miguel de Cervantes (2006), Prieto, Guillermo, Memorias de mis tiempos 1828-1840, Ed. facsímil, Alicante, pp. 88-94. Reproducción digital de la edición de París; México: Vda. De C. Bouret, 1906, en 〈http://www.cervantesvirtual.com〉 [10 de julio de 2008].

Fuente: 〈http//www.e-local.gob.mx> [12 de julio de 2008]. 